\title{
MANAJEMEN SATUAN PAUD DITINJAU DARI STANDAR PENGELOLAAN DALAM PENINGKATAN MUTU KELEMBAGAAN
}

\author{
Devi Sulaeman
}

Receive: $10 / 01 / 2021$

Accepted:03/02/2021

Published: 01/03/2021

\begin{abstract}
Abstrak
In improving the quality of education there is an important part that must be considered one of which is the accreditation of education. The quality of educational institutions can be measured through assessment indicators in accreditation instruments that contain 8 national education standards. data from BAN PAUD and PNF of West Java Province on the achievement of accreditation in 2018 as many as 111 early childhood education Unit with 8 National Standards Standard Levels of Child Development Achievement 31.65\%, Content Standards 74, 77\%, Process Standards 61, 98, Standards for Educators and Staff Education 82, 48\%, Infrastructure Standards 71, 92\%, Management Standards 54.88\%, Financing Standards $65.54 \%$ and Standard Assessment 55.29\%. From these data the need for auditing management in improving quality and seeing the readiness of the Institute to accreditation. The research objective is to a. Reviewing how early childhood educationUnit management is viewed from Management Standards to improve Institutional quality, $b$. Knowing the results of Institutional quality improvement. C. Analyze the problems faced by the Principal / early childhood educationUnit Manager in early childhood educationUnit management in terms of Management Standards to improve Institutional quality. $d$. Knowing the future improvement efforts carried out by the early childhood educationUnit and the Office of Education in improving Institutional quality. The results of Research Managers compile Vision and Objectives in accordance with the potential of institutions and the environment of early childhood educationinstitutions and make work plans related to 8 standards adjusted to budget plans that will be accepted. Coaching is carried out regularly by the Oversight and Foundation and Managers and teachers are included in the training activities.
\end{abstract}

Kata Kunci: management, early childhood education, management standards, institutional quality 


\section{PENDAHULUAN}

Pendidikan adalah usaha sadar dan terencana untuk mewujudkan suasana belajar dan proses pembelajaran agar peserta didik secara aktif mengembangkan potensi dirinya untuk memiliki kekuatan spiritual keagamaan,

Pendidikan anak usia dini di Indonesia memiliki kekhasan dibanding dengan yang diterapkan di berbagai negara. Kekhasan tersebut pada: (1) cakupan rentang usia, sasaran anak usia dini di Indonesia dari $0-6$ tahun, sedangkan di berbegai negara mencapai usia 8 tahun; (2) program layanan anak usia dini di Indonesia terdiri atas Taman Kanak-Kanak (untuk anak 4-6 tahun), Kelompok Bermain (prioritas anak usia 24 tahun), Taman Penitipan Anak (prioritas usia 06 tahun), dan Satuan PAUD Sejenis (anak 0-6 tahun); (3) jalur pendidikan. Taman KanakKanak masuk dalam jalur pendidikan formal, sedangkan Kelompok Bermain, Taman Penitipan Anak, dan Satuan PAUD Sejenis masuk dalam jalur pendidikan non formal. Kekhasan tersebut menjadikan PAUD di Indonesia spesifik dalam penyelenggaraannya karena setiap program layanan memiliki kekhasan masing- masing. Namun demikian semua program layanan PAUD memiliki tujuna yang sama yakni mengembangkan seluruh potensi anak.

Pendidikan anak usia dini harus dipersiapkan secara terencana dan bersifat Holistik Integratif agar di masa emas perkembangan anak mendapatkan stimulasi yang utuh, untuk mengembangkan berbagai potensi yang dimilikinya. Upaya yang dapat dilakukan dalam rangka pengembangan potensi tersebut melalui program pendidikan yang terstruktur. Untuk itu diperlukan layanan pendidikan bermutu yang dapat diselenggarakan oleh lembaga pendidikan yang telah memenuhi krieria minimal yang dipersyaratkan dalam Standar Nasional Pendidikan".

Pendidikan anak usia dini termuat dalam Undang-Undang Nomor 20 Tahun 2003 tentangSistem Pendidikan Nasional Pasal 28. Kementerian Pendidikan dan Kebudayaan telah memiliki arah pembangunan PAUD 2011- 2045 yang dibagi dalam 5 tahap (Tim Penyusun Kurikulum PAUD dalam Pedoman Kurikulum PAUD Dirjen PAUD dan PENMAS, 2015 : 2) yakni:

(1) Tahapperluasanlayanandaritahun 2002 2011 tahun,
(2) Tahappemantapanmutudaritahun 2011 2015 ,

(3) Tahapstandarisasimutunasionaldaritahun 2015 - 2025 tahun,

(4) Tahapstandarmutuinternasionaltahun 2025 -2035 , dan

(5) Tahaplayananparipurnatahun 2035 - 2045. Denganarahpembangunanjangkapanjangde mikiandiharapkantahun 2045 di saat Indonesia mencapai usia kemerdekaan ke100 tahun, anak Indonesia tumbuh dan berkembang menjadi manusia yang cerdas komprehensif.

Untuk mencapai tujuan ideal di atas, maka diperlukan manajemen lembaga pendidikan yang sesuai standar pengelolaan pendidikan sekolah yang telahdisahkandanberlaku di Indonesia yaitupermendikbudnomor 137 tahun 2014. Permendikbudnomor 137 tahun 2014 yang berisikan 10 babdan 38 pasal ini di atur tentang delapan standar yaitu: Standar Tingkat Pencapaian Perkembangan Anak, Standar Isi, Standar Proses, StandarPenilaian, StandarPendidikdan Tenaga Kependidikan, Standar Sarana dan Prasarana, Standar Pengelolaan,dan Standar Pembiayaan.

Standar pengelolaan PAUD merupakan pelaksanaan yang mengacupadastandarisi, proses, pendidik dan tenaga kependidikan, sarana dan prasarana, serta pembiayaan. Sebagaimana dituangkan dalam. PermendikbudNomor 137 tahun 2014 pasal 33 sampai 34.

Dalam peningkatan mutu pendidikan terdapat bagian penting yang harus diperhatikan diantaranya, syarat kelulusan peserta didik, akreditasi penyelenggaraan pendidikan serta kurikulumpendidikan.

Akreditasi merupakan penilaian kelayakan suatu program berdasarkan kriteria yang telah ditetapkan yaitu 8 Standar Nasional Pendidikan pada jalur pendidikan formal dan non formal serta di setiap jenjang dan jenis pendidikan untuk memberikan penjaminan mutu pendidikan, diselenggarakan oleh badan evaluasi mandiri yang menetapkan kelayakan program dan/atau satuan pendidikan dengan mengacu pada Standar Nasional Pendidikan sebagai bentuk akuntabilitas publik yang diatur dalam Permendikbud Nomor 13 tahun 2018 Tentang Badan Akreditasi Nasional Sekolah/Madrasah dan Badan Akreditasi Nasional 
Pendidikan Anak Usia Dini dan Pendidikan Nonformal.

Akreditasi dilaksanakan mulai dari Jenjang Pendidikan anak Usia Dini yang merupakan pendidikan fundamental dalam membetuk karakter bangsa. Tujuan Akreditasi sebagai penjaminan dan pengendalian mutu pendidikan. Adapun manfaat yang diharapkan dalam penyelenggaraan akreditasi di satuan Pendidikan Anak Usia dini antara lain : (1) membangun budaya mutu secara berkelanjutan, terencana dan kompetitif di tingkat kabupaten/ Kota, Provinsi, Regional, Nasional bahkan internasional, (2). Mendorong Satuan Paud dan PNF agar selalu berupaya meningkatkan mutu progranPaud dan PNF, (3). Memanfaatkan semua informasi hasil Akreditasi yang handal dan akurat sebagai umpan balik dalam upaya meningkatkan Kinerja Satuan Paud dan PNF, (4) Sebagai Peta mutu Pendidikan di satu wilayah dan secara Nasional, (5) dapat mengakses sumber daya pendidikan dari pemerintah dan masyarakat.

Mutu lembaga pendidikan dapat diukur melalui indikator penilaian dalam instrumen akreditasi yang memuat 8 standar nasional pendidikan mulai dari Standar Tingkat Pencapaian Perkembangan bagi Pendidikan Anak Usia Dini, Standar Isi yang berkaitan dengan Kurikulum yang yang dirumuskan oleh lembaga, Standar Proses , standar Pendidik dan Tenaga kependidikan, Standar Sarana dan Prasarana, Standar pengelolaan, Standar Pembiayaan dan Standar Penilaian.

Berdasarkan Data Analisis Capaian Akreditasi untuk satuan PAUD dari BAN PAUD dan PNF Nasional tahun 2017 dilihat dari 8 Standar Nasional Pendidikan bahwa Presentase Hasil capaian akreditasi mulai Standar STPPA mencapai $(76,48 \%)$, Standar Isi $(77,55 \%)$, Standar Proses $(71,03 \%)$, Standar Pendidik dan Tenaga Kependidikan (79,09\%), Standar Sarana dan Prasarana $(78,64 \%)$, Standar Pengelolaan $(59,31$ $\%)$, Standar Pembiayaan $(67,65 \%)$ dan Standar Penilaian $(65,67 \%)$.

Sedangkan menurut data dari BAN PAUD dan PNF Propinsi Jawa Barat yang diambil dari buku Profil BAN PAUD dan PNF Jawa Barat pada tahun 2018 capaian akreditasi di tahun 2018 sebanyak 111 Satuan PAUD dengan capaian 8 Standar Nasional Standar Tingkat Pencapaian perkembangan anak 31,65\%, Standar Isi 74, 77\%,
Standar Proses 61, 98, Standar Pendidik dan Tenaga Kependidikan 82, 48\%, Standar Sarana Prasarana 71, 92\%, Standar Pengelolaan 54,88\%, Standar Pembiayaan $65,54 \%$ dan Standar Penilaian 55,29\%.

Dari data tersebut dapat disimpulkan bahwa secara umum kualitasStandarPengelolaan PAUD masih memerlukan penguatan manajemen. Karena faktanyalembaga PAUD yang berada di Provinsi Jawa Barat ketika proses akreditasiyang dilaksanakan secarafisikadministrasiditinjau dari standar pengelolaan seperti, dokumenVisimisidan tujuan sekolah, Rencanakerja lima tahunan(RKLT), RencanaKerjaTahunan (RKT), Supervisi Kinerjadan Supevisi Program memiliki, namun tidak dapat diimplementasikan dan dokumen. Perencanaan yang ditemukan tidak ada kesinambungan satu sama lainnya. Begitupun dengan Sistem informasi Manajemen belum memadai dan terlaksana dalam mendukung administrasi pendidikan yang efektif, efisien dan akuntabel. Dari fakta masalah tersebut dapat disimpulkan bahwa Kepala sekolah/Pengelola PAUD kurang memahami Pengelolaan Lembaga. Adapun masalah terkait dengan manajemen lembaga yang ditemukan di lapangan adalah sebagai berikut:

1. Kepalasekolah/ pengelolalembaga PAUD tidakmembuat program kerjaberdasarkan karakteristik lembaga masing-masing dantidakmelaksanakansupervisi.

2. Satuan PAUD hanya mempersiapkan dokumen guna kepentingan Akreditasi tanpa diimplementasikan.

3. Kurangnyapembinaandariyayasandanpenilik/ pengawas dalam manajemen lembaga.

Sehingga perlu adanya pembinaan manajemen lembaga PAUD yang dipersiapkandalammenghadapi proses akreditasi guna peningkatan mutu pendidikan yang lebih baik. Diperlukan peran pemerintah Daerah yang harus terus mendorong dan mengembangkan sekolah dengan menerapkan konsep manajemen "Manajemen Peningkatan Mutu Berbasis Sekolah (MPMBS), yaitu usaha peningkatan mutu pendidikan dengan menggalang segala sumber daya yang ada di sekolah dan lingkungannya, baik guru, orangtua siswa, pemerintah setempat maupun swasta agar terkoordinasi dan terencana dalam menunjang peningkatan mutu pendidikan di sekolahnya (Rusdiana., 2015 : 167) 


\section{KAJIAN LITERATUR}

Standar Pengelolaan adalah Standar Nasional Pendidikan yang berkaitan dengan perencanaan, pelaksanaan, dan pengawasan kegiatan pendidikan pada tingkat satuan pendidikan, kabupaten/kota, provinsi, atau nasional agar tercapai efisiensi dan efektivitas penyelenggaraan pendidikan

Akreditasi merupakan penilaian kelayakan suatu program berdasarkan kriteria yang telah ditetapkan yaitu 8 Standar Nasional Pendidikan pada jalur pendidikan formal dan non formal serta di setiap jenjang dan jenis pendidikan untuk memberikan penjaminan mutu pendidikan, diselenggarakan oleh badan evaluasi mandiri yang menetapkan kelayakan program dan/atau satuan pendidikan dengan mengacu pada Standar Nasional Pendidikan sebagai bentuk akuntabilitas publik

\section{METODE PENELITIAN}

Penelitian tentang manajemen Satuan PAUD ditinjau dari Standar Pengelolaan untuk meningkatkan mutu pendidikan Anak Usia Dini, menggunakan jenis pendekatan kualitatif, suatu proses penelitian dan pemahaman berdasarkan pada metodologi yang menyelidiki fenomena sosial dan masalah manusia. Peristiwa yang terjadi di lingkungan masyarakat, aktivitas social, sikap, kepercayaan, persepsi, dan segala bentuk pemikiran orang ataupun kelompok.

Menurut Sukmadinata (2010) Pendekatan kualitatif digunakan karena mempunyai dua tujuan penting yaitu, pertama menggambarkan dan mengungkap, kedua menggambarkan dan menjelaskan. Dengan cara inilah diharapkan penelitian yang dilakukan dapat menggambarkan kondisi objek secara objektif serta mampu mengungkapkanyakepermukaan dan mampu menjelaskanya secara objektif.

Lingkup masalah yang akan dikaji adalah tentang manajemen Satuan PAUD ditinjau dari Standar Pengelolaan untuk meningkatkan mutu Manajemenpendidikan Anak Usia Dini. Setiap fenomena yang ditemukan ditulis dalam lembaran catatan wawancara atau observasi atau dokumen. Fokus penelitian ini dibatasi:

1. Kegiatan manajemen Satuan PAUD ditinjau dari Standar Pengelolaan untuk meningkatkan mutu Kelembagaan.

2.Hasil dari peningkatan mutu Kelembagaan.

3. Masalah yang dihadapi oleh Kepala sekolah/ Pengelola PAUD dalam manajemen Satuan
PAUD ditinjau dari Standar Pengelolaan untuk meningkatkan mutu Kelembagaan.

4. upaya dari Satuan PAUD dan Dinas Pendidikan untuk mengatasi masalah manajemen Satuan PAUD ditinjau dari Standar Pengelolaan untuk meningkatkan mutu Kelembagaan.

Objek penelitian tentang manajemen Satuan PAUD ditinjau dari Standar Pengelolaan untuk meningkatkan mutu kelembagaan akan dilaksanakan di Provinsi Jawa Barat dengan mengambil KabupatenKarawang. Dasar pemilihan lokasi penelitian sekolah ini adalah Jumlahlembaga PAUD terus meningkattajam, pada tahun 2002 Uji coba DIREKTORAT PAUD di Kabupaten Karawang terdapat 20 lembaga di dua Kecamatan yaitu Kecamatan Karawang dan Kecamatan Klari, dengan Jumlah Pendidik sebanyak 40 orang,Seiring dengan berjalannya waktu yang terus bergulir jumah Lembaga PAUD pun pada tahun 2019 ini terdapat KB : 53, TPA : 3, SPS : 951 : 1007 (berdasarkan data dapodik) dengan jumlah Pendidik 2.918 dengan jumlah anak yang terlayani sebanyak 30.201 anak yang dilayani.

Capaian akreditasi dari tahun 2010 s.d 2019 untuk Pendidikan AnakUsia Dini adalah 204 Satuan Pendidikan AnakUsia Dini yang terakreditasi. Dari perkembangan data dapatdilihatbahwaajuanakreditasicukuprendahhan yasekitar 20\% darijumlahsatuan Pendidikan anakusiadini yang ada.

Menurut data dari BAN PAUD dan PNF PropinsiJawa Barat yang diambildaribukuProfil BAN PAUD dan PNF Jawa Barat padatahun 2018 capaianakreditasi di tahun 2018 sebanyak 111 Satuan PAUD dengancapaian 8 Standar Nasional Standar Tingkat Pencapaianperkembangananak 31,65\%, Standar Isi 74, 77\%, Standar Proses 61, 98, StandarPendidikdan Tenaga Kependidikan 82, 48\%, StandarSaranaPrasarana 71, 92\%, StandarPengelolaan 54,88\%, StandarPembiayaan 65,54\% danStandarPenilaian 55,29\%.

Penggunaan teknik operasional dan alat pengumpulan data yang tepat memungkinkan diperolehnya data yang objektif. Adapun teknik pengumpulan data yang digunakan dalam penelitian ini adalah :

1. Observasi

Observasi yang dilakukan adalah observasi partisipatif yaitu pengumpulan data yang fokus perhatiannya adalah pemahaman dan 
kemampuan peneliti dalam memaknai suatu fenomena yang terjadi. Peneliti dalam penelitian ini benar-benar menempatkan diri sebagai pengamat, yaitu hanya melakukan pengamatan, pengambilan gambar (foto) dan menyusun peristiwa-peristiwa yang terjadi.

2. Wawancara

Wawancara adalah teknik percakapan atau Tanya jawab yang diarahkan untuk mendapatkan informasi tertentu. Wawancara dilakukan dengan cara tatap muka secara langsung dengan pihak-pihak terkait dengan penelitian. Peralatan yang digunakan adalah perekam suara.

3. Studi Dokumentasi

Data sekunder yang berhasil dikumpulkan oleh peneliti dibutuhkan untuk melengkapi datadata yang diperlukan sebagai informasi pendukung dalam penelitian. Data-data tersebut anatara lain dokumen perencanaan program sekolah, dokumentasi pelaksanaan dan dokumen supervisi yang didokumentasikan

Dalam penelitian kualitatif, analisis data dilakukan sejak awal penelitian dan selama proses penelitian dilaksanakan. Data diperoleh, kemudian dikumpulkan untuk diolah secara sistematis. Dimulai dari wawancara, observasi, mengedit, mengklasifikasi, mereduksi, selanjutnya aktivitas penyajian data serta menyimpulkan data. Teknis analisis data dalam penelitian ini menggunakan model analisis interaktif. Analisis data seperti ini dikenal sebagai model Miles andHuberman. Miles andHuberman (Herdiansyah, 2010) mengemukakan bahwa aktivitas dalam analisis data kualitatif dilakukan secara interaktif dan berlangsung secara terus-menerus sampai tuntas, sehingga datanya sudah jenuh. Aktivitas dalam analisis data melalui langkah-langkah sebagai berikut :

a) Reduksi data

Reduksi data merupakan proses pengumpulan data penelitian. Selama proses reduksi peneliti dapat melanjutkan meringkas, mengkode, menemukan tema. Proses reduksi berlangsung selama penelitian di lapangan sampai pelaporan selesai.

b) Display Data

Penyajian berupa teks naratif. Biasanya dalam penelitian mendapat data yang banyak, data-data ini tidak mungkin dipaparkan secara keseluruhan, untuk itu dalam penyajian data penelitian dapat dianalisis oleh peneliti untuk disusun secara sistematis, atau simultan, sehingga data yang diperoleh dapat menjelaskan atau m,enjawab masalah yang di teliti.

c) Mengambil Kesimpulan/ Verifikasi Data

Mengambil kesimpulan merupakan analisis lanjutan dari reduksi data, dan display data sehingga data dapat disimpulkan dan peneliti masih ada peluang untuk menerima masukan. Penarikan kesimpulan sementara masih dapat diuji kembali dengan datang ke lapangan, dengan cara merefleksi kembali.

Disamping itu, peneliti dapat bertukar pikiran dengan teman sejawat, atau dengan cara triangulasi sehingga kebenaran ilmiah dapat mendekati kesempurnaan Intinya, data yang terkumpul dalam penelitian ini akan dianalisis dengan beberapa tahapan sebagaimana berikut : pertama, proses reduksi data dengan cara melakukan pemilahan dan klasifikasi data, kedua, melakukan pengorganisasian data menjadi satu kesatuan yang utuh, ketiga, melakukan interpretasi menyuluruh terhadap data dan terakhir menarik kesimpulan.

\section{HASIL DAN PEMBAHASAN}

Berdasarkan hasil penelitian dapat diketahui bahwa di PAUD Adityadan PAUD Plamboyan 3, Pengelola membuat perencanaan pengelolaan lembaga dengan melibatkan guru sebagai pelaksana program. Pengelola menyusun Visi Misi dan Tujuan sesuai dengan potensi lembaga dan lingkungan lembaga PAUD serta membuat Rencana kerja terkait 8 standar disesuaikan dengan rencana anggaran yang akan diterima.

Pembinaanpenilik: supervise kinerja pengelola oleh penilik dilaksanakan secara berkala 3 bulan sekali untuk melihat pelaksanaan administrasi dan pendokumentasian kegiatan dilaksanakan secara konsisten sehingga Lembaga telah siap untuk di akreditasi

Pembinaan dari yayasan kepada pengelola lembaga dilakukan dengan cara diikutsertakan dalam diklat manajaemen, supervise dan kepemimpinan agar pengelola dapat merumuskan dan memahami manajemen kelembagaan. 
Guru diikutsertakandalampelatihan professional keguruan sehingga guru faham administrasi dan dapat mengimplementasikan.

\section{KESIMPULAN}

Dalam peningkatan mutu pendidikan terdapat bagian penting yang harus diperhatikan salah satu diantaranya adalah akreditasi penyelenggaraan pendidikan. Mutu lembaga pendidikan dapat diukur melalui indikator penilaian dalam instrumen akreditasi yang memuat 8 standar nasional pendidikan. Hasil penelitian menunjukkan bahwa lembaga PAUD yang menjadi tempat penelitian telah merencanakan program, melaksanakan program sesuai visi misi dan tujuan lembaga, melaksanakan pengadministrasian serta mengevaluasi program dengan kegiatan supervisi oleh Penilik dan Yayasan secara berkala sehingga lembaga yang diteliti siap untuk mengajukan akreditasi.

\section{REFERENSI}

Ali, Mohammad. 2009. Pendidikan untuk Pembangunan Nasional, PT Imperial Bhakti Utama

Asmawati. L. 2014.Perencanaan Pembelajaran PAUD. Bandung: PT RemajaRosdakarya.

BukuPedoman K-13. Kementerian Pendidikan Dan KebudayaanDirektoratenderal Pendidikan AnakUsia Dini dan Pendidikan Masyarakat. DirektoratPembinaan Pendidikan AnakUsia Dini Tahun 2015

Moleong. 2000. MetodologiPenelitianKualitatif. Bandung: PT RemajaRosdakarya.

Mulyasa, E. 2009. ManajemenBerbasisSekolah. Bandung: PT RemajaRosdakarya.

Mulyasa, E. 2012. Manajemen PAUD. Bandung: PT RemajaRosdakarya.

NuraniSujiono.Y, Sujiono. $\quad$ B, 2010. BermainKreatifBerbasisKecerdasanJamak, Jakarta : PT Indeks

PeraturanPemerintahNomor 32 Tahun 2013 tentangPerubahanAtasPeraturanPemerintah No.19 Tahun 2005 tentangStandar Nasional Pendidikan
Peraturan Presiden Republik Indonesia Nomor 60 tahun 2013

Peraturan Menteri Pendidikan Nasional Nomor 63 Tahun 2009 tentangSistemPenjaminanMutu Pendidikan

PeraturanPemerintahRepublik Indonesia No.13 Tahun 2015 tentang Perubahan Kedua Atas PeraturanPemerintah No.19 Tahun 2005 tentangStandar Nasional Pendidikan

PermendikbudNomor 137 tahun 2014 tentangStandar PAUD

PermendikbudNomor 146 tahun 2014 tentangKurikulum PAUD

Rusdiana. 2015, Kebijakan Pendidikan dariFilosofikeImplementasi, Bandung, CV. Pustaka Setia

Sugiyono.2009. MetodePenelitianKualitatif Dan $R \&$ $D$, Bandung : Alfabeta

Suyadi, dan U, Maulidya. 2013. Konsep Dasar PAUD, Bandung: PT RemajaRosdakarya. 